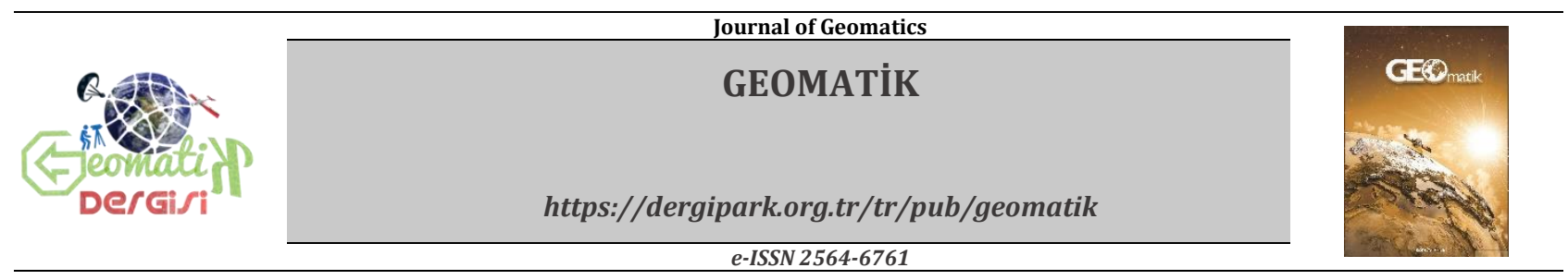

\title{
Türkiye ve Çevresinde SRTM Sayısal Yükseklik Modelinin Doğruluğu
}

\author{
İbrahim Öztuğ BÍLDİRİCi*, Ramazan Alpay ABBAK \\ Konya Teknik Üniversitesi, Mühendislik ve Doğa Bilimleri Fakültesi, Harita Mühendisliği Bölümü, Konya, Türkiye
}

Anahtar Kelimeler

Sayısal yükseklik modeli

Topoğrafya

Doğruluk

\begin{abstract}
ÖZ
Son yıllarda 1 yay saniye çözünürlüklü SRTM verileri yüksek çözünürlüklü global modeller içinde önemli bir veri kaynağı olarak ilgili alanlarda kullanılmaktadır. $\mathrm{Bu}$ çalışmada topografik haritaların sayısallaştırılması yoluyla elde edilen yerel veriler ile SRTM SYM karşılaştırılmıştır. İki sistemin yükseklik başlangıcı da aynı olmadığından karşılaştırmalar düşey datum dönüşümü yapılarak gerçekleştirilmiştir. Elde edilen sonuçlar Türkiye ve yakın çevresini kapsayan SRTM verilerinin global doğruluk değerlerinden daha yüksek doğrulukta olduğu görülmüştür. SRTM'de iki paftada mevcut boşluklar da doldurulup, düșey datum EGM08'e dönüştürülmüştür.
\end{abstract}

\section{Accuracy of SRTM DEM in Comparison to Local Data within Turkey and its Vicinity}

\section{Keywords}

Digital elevation model

Topography

Accuracy

\begin{abstract}
In recent years, Shuttle Radar Topography Mission (SRTM) one-arc-second data has been used in related areas as an important data source. In this study SRTM digital elevation model (DEM) is compared to local DEM created by contour lines of topographic quadrangles. Since the vertical datum of two data sets are different the comparisons are performed after an appropriate datum transformation. Results show that the accuracy of SRTM one-arc-second data in Turkey are higher than the global accuracy estimates. Void data that are presented in two tiles are filled from local data, and all tiles within and around Turkey are converted to EGM08 vertical datum.
\end{abstract}

\section{GíRiş}

Yeryüzü kara parçalarının büyük bölümlerini kapsayan global sayısal yükseklik modelleri, uzaktan algılama yöntemleri ya da var olan topografik haritaların sayısallaştırılması ile üretilmekte ve ticari ya da ticari olmayan biçimlerde kullanıcılara sunulmaktadır. Bu kapsamda ticari olmayan kategoride hayata geçen çalıșmalardan biri Shuttle Radar Topography Mission (SRTM), Mekik Radar Topografya Görevi'dir. NASA (National Aeronautics and Space Administration) tarafindan gerçekleştirilen projede yeryüzünün $\pm 60^{\circ}$ enlemleri arasındaki kara parçaları SAR (Synthetic-aperture radar) tekniği ile taranmıştır. Görev, 2000 yılı Şubat ayında 11 gün devam etmiştir. İyileştirme *Sorumlu Yazar *(iobildirici@ktun.edu.tr) ORCID ID 0000-0001-7717-586X (raabbak@ktun.edu.tr) ORCID ID 0000-0002-6944-5329 çalışmalarından sonra SRTM Sayısal Yükseklik Modeli (SYM) üç değişik versiyonda dağıtılmaktadır.

$\mathrm{Bu}$ çalışmada SRTM Global olarak da adlandırılan SRTM 1" çözünürlüklü veri seti incelenmiş olup, bundan sonra SRTM1 olarak anılacaktır.

Ülke bazında yerel yükseklik verilerinden üretilen SYM çalıșmaları da yapılmaktadır. $\mathrm{Bu}$ bağlamda Türkiye'de Harita Genel Müdürlüğü tarafından 1:25 000 ölçekli topografik haritaların eş yükseklik eğrilerinin sayısallaştırılması ile elde edilen bir SYM hazırlanmıștır (Yerel SYM).

$\mathrm{Bu}$ çalışmada Selçuk Üniversitesi BAP Koordinatörlüğü tarafından desteklenen ve yazarların gerçekleștirdiği "1 Yay Saniyesi Çözünürlüklü Türkiye Sayısal Yükseklik Modelinin 
Oluşturulması ve Kullanım Olanaklarının Araştırılması" başlıklı proje sonuçlarının bir kısmı paylaşılacaktır (Bildirici ve Abbak, 2019). Bu projede global SYM'lerin doğrulukları daha doğru olduğu bilinen yerel SYM ve DGNSS izleri ile karşılaştırılarak analiz edilmiş, SRTM1 veri boşlukları yerel SYM'den yararlanılarak tamamlanmıştır. Veri seti daha sonra EGM08 datumuna dönüştürülerek TSYM1 olarak adlandırılmış ve İnternet üzerinden yayınlanmıştır.

Elde edilen sonuçlara göre Türkiye ve yakın çevresinde SRTM1 karesel ortalama hatası $\pm 7-9 \mathrm{~m}$ arasında olup global doğruluğa göre $( \pm 16 \mathrm{~m})$ daha iyidir.

İkinci bölümde konu ile ilgili önemli kaynakların özeti verilmiş, üçüncü bölümde SRTM ve yerel SYM tanıtılarak doğruluk araştırması ve boşluk doldurma metodolojisi verilmiş, dördüncü bölümde doğruluk ve boşluk doldurma üzerine yapılan çalışmalar ve sayısal sonuçları verilmiştir. Sonuç ve öneriler son bölümde yer almaktadır.

\section{KAYNAK ARAŞTIRMASI}

Global SYM'lerin Türkiye'yi kapsayan veri setleri üzerinde yapılan ilk çalışmalara Bildirici vd. (2008) tarafından gerçekleştirilen proje örnek gösterilebilir. 0 dönemde ücretsiz kullanım olanağl bulunan tek global SYM, boşluklar içeren 3" çözünürlüklü SRTM idi. Bu veri seti yerel yükseklikler ile karşılaştırılmış, $10 \mathrm{~m}$ civarında doğruluğu olduğu bulunmuş, veri boşlukları yerel veri kaynaklarından yararlanılarak doldurulmuştur. Elde edilen yeni SYM ilgili kullanıcılara yayınlanmıștır (http://galileo.ktun.edu.tr/tsym3).

Abbak (2014) SRTM ve ASTER modellerinin jeoit modellemeye katkısını ele almıştır. Öncelikle Fransa'nın Auvergne test bölgesi için bu iki modelin doğruluk analizleri GPS-Nivelman verileriyle gerçekleştirilmiştir. ASTER modelinin daha düşük doğruluklu olduğu belirlenmiştir. Daha sonra ASTER ve SRTM modelleri kullanılarak gravimetrik jeoit belirlenmiştir. ASTER modeli doğruluk açısından daha düşük olmasına karşın jeoit belirlemede SRTM ile benzer sonuçlar vermiştir.

Luana vd. (2015) Çin'in Shandong eyaletinin kıyısı boyunca ASTER ve SRTM modellerinin doğruluk analizlerini gerçekleştirmiştir. Referans verisi olarak 1:50000 ölçekli haritaların sayısallaştırılması sonucu elde edilen SYM kullanılmıştır. SRTM doğruluğu \pm 13.74 m, ASTER 1. Versiyon $\pm 42.11 \mathrm{~m}$, ASTER 2. Versiyon ise $\pm 12.12 \mathrm{~m}$ bulunmuştur.

Tibet'in güneydoğusundaki dağlık bir bölgede ASTER, SRTM ve TANDEM-X sayısal yükseklik modellerinin jeomorfolojik (eğim ve yükseklik) açıdan karşılaştırılması yapılmıştır (Pipaud vd., 2015). Sonuçlar, SRTM ve TANDEM-X'in daha uyumlu olduğunu ve TANDEM-X'in oldukça başarılı sonuçlar verdiğini göstermektedir.

ASTER sayısal yükseklik modeli jeomorfolojik çalışmalar açısından değerlendirilmiştir (White v.d.,
2015). Namibya ve Kalahari'de bir uygulama gerçekleștirilmiştir. Metre altı doğruluklu DGNSS verileri ile yapılan karşılaştırmada ASTER oldukça iyi sonuçlar vermiştir.

SRTM'in düşey datumunun EGM96 yerine EGM08 kullanılması durumunda elde edilecek iyileşme miktarı Türkiye sınırları içerisinde incelenmiştir (Ustun v.d., 2018). Sonuçlar, Türkiye'nin Doğu Karadeniz bölgesinde ve Osmaniye-G. Antep yöresinde $\pm 5-6$ metreye varan doğruluk artışı olduğunu göstermiştir.

\section{MATERYAL ve METOT}

\subsection{SRTM}

SRTM projesinde Endeavour uzay mekiğine monte edilen radar sistemi, 2000 yll Şubat ayında yeryüzü kara parçalarının $\pm 60^{\circ}$ enlemleri arasında kalan kısmında veri toplamıştır (JPL, 2018). Mekik üzerinde monte edilmiş olan $\mathrm{C}$ bant alglayıcısı NASA'ya X bant algılayıcısı ise Alman İtalyan uzay ajanslarına aittir. 2004 yılında NASA C bant verilerinden oluşturduğu SRTM sayısal yükseklik modelini ABD bölgesi için 1" diğer bölgeler için ise 3" çözünürlükte ücretsiz olarak kullanıma açmıştır. Daha sonra veriler üzerinde düzeltmeler ve boşluk doldurma çalışmaları yapılmıştır. Bu çalışmalara paralel olarak vektör formatta su kütleleri verisi (SWBD: SRTM Water Body Data) oluşturulmuştur. $\mathrm{Bu}$ veriler SRTM1'den elde edilmiștir. Günümüzde SRTM kapsamında üç SYM bir çizgisel vektör veri olmak üzere 4 veri seti Earth Explorer veri portali üzerinde kullanıma sunulmuş durumdadır (USGS, 208). Bunlar,

- Boşluklu SRTM 1" çözünürlüklü (SRTM1),

- Boşlukları doldurulmuş SRTM 3" çözünürlüklü (SRTM3),

- Boşlukları doldurulmamış SRTM 3" çözünürlüklü (SRTM3),

- Su kütleleri verisi (SWBD), olarak siralanır.

Veri toplama yönteminden kaynaklanan nedenlerle veri boşlukları oluşmuştur. Bu tür noktalarda yüksekliğin belirlenemediği -32768 tam sayısı ile ifade edilmiş olup, (void data) olarak adlandirılır.

Verilerin özellikleri Tablo 1'de gösterilmiștir. SRTM1 verilerinin $\pm 50^{\circ}$ enlemleri dıșındaki bölgelerde meridyen ve paraleller yönünde farklı çözünürlükte olduğuna dikkate edilmelidir.

Tüm SRTM verileri $1^{\circ} \times 1^{\circ}$ boyutlu bir bölgeyi içeren dosyalar halinde kullanıma sunulmuştur. $\mathrm{Bu}$ bölgeler kaynaklarda tile olarak adlandırılmıș olup, burada pafta olarak anılacaktır.

SRTM verileri ile çalışılırken verilerin güncellik durumunun farkında olunmalıdır. SRTM, 2000 yıl Şubat ayındaki yeryüzü topoğrafyasını yansıtmaktadır. 


\subsection{Yerel SYM}

Ülke bazında SYM elde etmek üzere Harita Genel Müdürlüğü (HGM) tarafından 1:25 000 ölçekli topografik haritaların eş yükseklik eğrilerinin otomatik vektörizasyonu ile YUKPAF adı verilen veriler oluşturulmuştur. Bu veriler 1:25 000'lik pafta bazında vektör CAD dosyaları biçiminde düzenlenmiştir. Daha sonra global SYM çalışmalarında kullanılan DTED2 formatında 1" çözünürlüklü SYM haline getirilmiştir. Veri seti özellikleri düşey datumunun yerel olması (Antalya mareograf istasyonunun ortalama deniz düzeyi) dışında SRTM1 ile aynıdır. Hizmete özel statüde olan veriler kamu kurum ve kuruluşlarına ücret karşılığı sağlanmaktadır (HGM, 2018).

Tablo 1. SRTM veri setlerinin özellikleri

\begin{tabular}{|c|c|c|c|c|}
\hline Set & Yatay Koord. & Düss. Dat. & Cözün. & Dosya Formatı \\
\hline SRTM 1" Global & WGS84, Coğrafi & EGM96 & $1^{\prime \prime *}$ & BIL, DTED, GeoTIFF \\
\hline SRTM Doldurulmuş & WGS84, Coğrafi & EGM96 & $3^{\prime \prime}$ & BIL, DTED, GeoTIFF \\
\hline SRTM Doldurulmamış & WGS84, Coğrafi & EGM96 & $3^{\prime \prime}$ & BIL, DTED, GeoTIFF \\
\hline SWBD & WGS84, Coğrafi & EGM96 & & ESRIShape \\
\hline
\end{tabular}

\subsection{Doğruluk Araștırması Metodolojisi}

Global SYM'lerin doğruluğu daha yüksek doğruluklu yerel veriler ile karşılaştırarak araştırılabilir. Kullanılan her iki SYM veri setinin yatay datumu WGS84'tür. Düșey datum SRTM'de EGM96, yerel SYM'de Antalya mareograf istasyonunun ortalama deniz düzeyidir. Bu nedenle global verilerin yerel verilerle karşılaştırmasını düşey datum farklılığını gözeterek yapmak daha doğru bir yaklaşımdır. Bu amaçla 4 parametreli datum dönüşümü yapılması öngörülmüştür. Geleneksel olarak datum dönüşümü,

$$
\begin{aligned}
H_{B}-H_{A} & =c_{0} \cos \varphi \cos \lambda+c_{1} \cos \varphi \sin \lambda \\
& +c_{2} \sin \varphi+c_{3}
\end{aligned}
$$

eşitliği ile ifade edilir. Bu şekilde $A$ datumundan $B$ datumuna dönüşüm tanımlanır. (1) eşitliğine alternatif olarak kaynaklarda daha fazla parametreli dönüşüm bağıntıları da yer almaktadır. Dengelemeli dönüşüm,

$$
\begin{aligned}
\boldsymbol{\Delta} \mathbf{H} & =\mathbf{A} \mathbf{c} \\
\mathbf{c} & =\left(\mathbf{A}^{\top} \mathbf{A}\right)^{-1} \mathbf{A}^{\top} \mathbf{\Delta} \mathbf{H} \\
\mathbf{A} & =\left[\begin{array}{cccc}
\cos \varphi_{1} \cos \lambda_{1} & \cos \varphi_{1} \sin \lambda_{1} & \sin \varphi_{1} & 1 \\
\cos \varphi_{2} \cos \lambda_{2} & \cos \varphi_{2} \sin \lambda_{2} & \sin \varphi_{2} & 1 \\
\ldots & \ldots & \ldots & \ldots
\end{array}\right] \\
\mathbf{c} & =\left[\begin{array}{c}
c_{0} \\
c_{1} \\
c_{2} \\
c_{3}
\end{array}\right] \\
\boldsymbol{\Delta} \mathbf{H} & =\left[\begin{array}{c}
H_{B_{1}}-H_{A_{1}} \\
H_{B_{1}}-H_{A_{1}} \\
\ldots
\end{array}\right]
\end{aligned}
$$

eşitlikleri ile bulunan parametrelerle (katsayılarla) gerçekleştirilir. Dönüşümün karesel ortalama hatası,

$$
\begin{aligned}
\mathbf{v} & =\mathbf{A c}-\mathbf{\Delta} \mathbf{H} \\
m_{0} & =\sqrt{\frac{\mathbf{v}^{\top} \mathbf{v}}{n-4}}
\end{aligned}
$$

şeklinde ifade edilebilir. Burada $n$ SYM dosyasındaki geçerli nokta sayısı olup 1" çözünürlüklü dosyalarda yaklaşık 13 milyondur (36012). Bu matris boyutu ile işlem yapılamayacağından hesaplamalar artımlı olarak yapılmalıdır. Belli bir nokta sayısı için belirlenen $\mathbf{A}^{\top} \mathbf{A}$ ve $\mathbf{A}^{\top} \boldsymbol{\Delta} \mathbf{H}_{\text {matrisleri }}$ sonraki her bir nokta için arttırılarak gidilir. $\mathrm{Bu}$ durumda $\mathbf{v}^{\top} \mathbf{v}$ hesabı da çok zor olacağından Ansermet bağıntısı kullanılabilir. Buna göre düzeltmelerin kareleri,

$$
\mathbf{v}^{\top} \mathbf{v}=\boldsymbol{\Delta} \mathbf{H}^{\top} \boldsymbol{\Delta} \mathbf{H}-\left(\mathbf{A}^{\top} \boldsymbol{\Delta} \mathbf{H}\right)^{\top} \mathbf{c}
$$

bağıntısı ile hesaplanabilir.

Doğruluk araștırması yapılırken araştırılan ve doğru kabul edilen SYM'ler arasında datum farklılığ yok ya da küçük ise doğrudan karşılaştırma da yapılabilir. $\mathrm{Bu}$ durumda yükseklik farklarının karesel ortalama hataları $(m)$, standart hataları $(s)$ ve ortalamaları $(\Delta \bar{H})$,

$$
\begin{aligned}
m & =\sqrt{\frac{\sum \Delta H^{2}}{n}} \\
s & =\frac{\sum|\Delta H|}{n} \\
\Delta \bar{H} & =\frac{\sum \Delta H}{n}
\end{aligned}
$$

bağıntıları ile hesaplanabilir.

Hem datum dönüşümünde hem de doğrudan karşılaştırmada verilerde kaba hataların bulunma olasılığına karşı tüm farklar hesaba alınmaz. Bu amaçla global bir doğruluk değeri biliniyor ise $(\sigma)$ bunun üç katını aşan farklar kaba hatalı kabul edilebilir. $\mathrm{Bu}$ değer SRTM için $16 \mathrm{~m}$ verilmiş olup, $3 \sigma=50 \mathrm{~m}$ alınabilir (JPL, 2018; LPDAAC, 2018).

$\mathrm{Bu}$ hesaplamaları gerçekleştirmek için Linux işletim sisteminde C dili ile kurum içi yazılımlar geliştirilmiştir. Bunlar SRTM formatlarını (HGT ya da BIL) işlediğinden farklı formatlardaki veriler (GeoTiff ya da DTED2) GDAL yazılım paketi ile dönüştürülmüştür (GDAL, 2018).

\subsection{Veri Boşluklarının Doldurulması}


Türkiye ve yakın çevresini kapsayan SRTM1 paftalarının ikisinde veri boşlukları bulunmaktadır. $\mathrm{Bu}$ boșluklar yerel SYM'den doldurulabilir. Doğrudan veri aktarmak yerine pafta bazında belirlenen datum dönüşümünün kullanılması doğru bir yaklaşım olacaktır.

Pafta bazında datum dönüșüm parametreleri farklı olduğundan boşluk doldurma işlemi sonunda paftalarda kenarlaşma problemleri oluşup oluşmadığı analiz edilmelidir. Veri boşlukları olan paftalarda boşluklar özellikle pafta kenarlarında olduğundan bu analiz önemlidir. Pafta kenarlarında aynı konuma sahip noktaların farklı yükseklikleri olması halinde aradaki fark yeterince küçük ise ( $3 \sigma$ 'dan küçük) iki yüksekliğin ortalaması iki paftaya da atanarak kenarlaşma sağlanır.

\section{ARAŞTIRMA}

Proje kapsamında SRTM1 ile aynı çözünürlükte olan HGM tarafından üretilmiş yerel SYM veri setinden değişik topografik özelliklere sahip 6 pafta temin edilmiştir. Yerel SYM paftalarının güney batı köşe koordinatları Tablo 2'de konumları Şekil 1'de verilmiștir.

Makalede kullanılan haritalar ise GMT yazılım paketi ile hazırlanmıştır (GMT, 2018).

Tablo 2. Araştırmada kullanılan yerel SYM paftaları

\begin{tabular}{llll}
\hline SYM No & $\varphi_{0}{ }^{*}$ & $\lambda_{0}^{*}$ & İsimlendirme \\
\hline 1 & $37^{\circ}$ & $31^{\circ}$ & N37E031 \\
2 & $37^{\circ}$ & $32^{\circ}$ & N37E032 \\
3 & $37^{\circ}$ & $34^{\circ}$ & N37E034 \\
4 & $37^{\circ}$ & $35^{\circ}$ & N37E035 \\
5 & $40^{\circ}$ & $40^{\circ}$ & N40E040 \\
6 & $40^{\circ}$ & $41^{\circ}$ & N40E041 \\
\hline
\end{tabular}

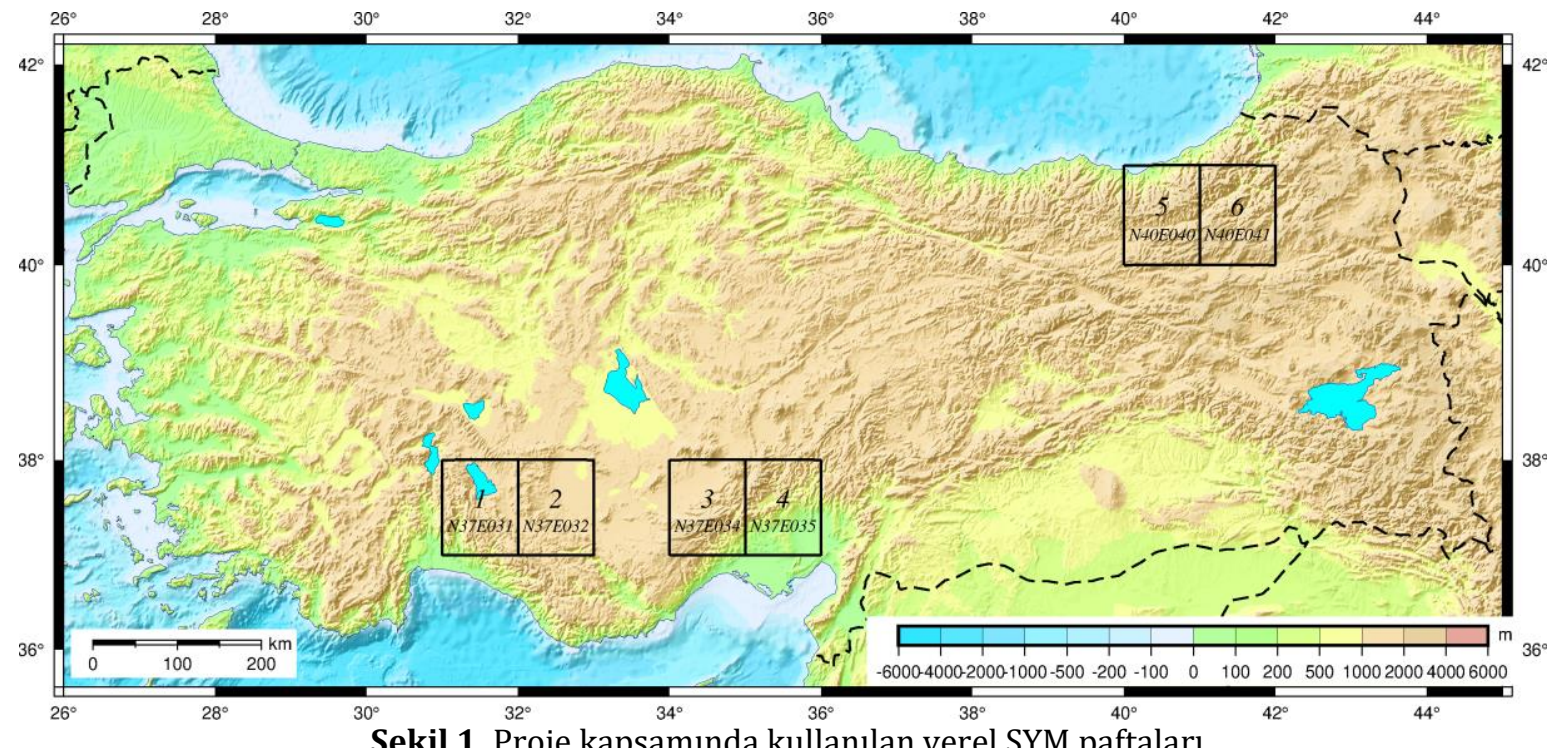

Tablo 3. Yerel SYM-SRTM1 datum dönüşümü

\begin{tabular}{lcccccccc}
\hline SYM No & $\varphi_{0}^{\circ}$ & $\lambda_{0}^{\circ}$ & $c_{0}(\mathrm{~m})$ & $c_{1}(\mathrm{~m})$ & $c_{2}(\mathrm{~m})$ & $c_{3}(\mathrm{~m})$ & $m_{0}(\mathrm{~m})$ & Oran $(\%)$ \\
\hline 1 & 37 & 31 & 12406.689 & 7441.042 & 11143.120 & -18257.713 & \pm 6.66 & 99.87 \\
2 & 37 & 32 & -5007.122 & -3176.247 & -4548.832 & 7475.918 & \pm 4.16 & 99.97 \\
3 & 37 & 34 & 4534.629 & 3098.918 & 4157.177 & -6886.497 & \pm 7.02 & 99.60 \\
4 & 37 & 35 & 35867.189 & 25447.689 & 34277.574 & -55752.095 & \pm 7.94 & 99.02 \\
5 & 40 & 40 & -20081.754 & -16937.807 & -22322.511 & 34475.950 & \pm 8.59 & 99.72 \\
6 & 40 & 41 & 18312.221 & 16075.797 & 20775.454 & -32017.113 & \pm 9.12 & 97.04 \\
\hline
\end{tabular}

\subsection{Yerel SYM ile SRTM1 Doğruluk Analizi}

Tablo 2'de verilen 6 dosya için datum dönüşümü yapılmıştır. Dönüşüm dengelemeli olarak yapılmış, iki farklı datumdaki noktaların yükseklik farkları SRTM'nin global doğruluğunun ( $\sigma=16 \mathrm{~m})$ üç katının altında ise dengelemeye dahil edilmiștir. Bu değer $50 \mathrm{~m}$ alınmıștır. Farklar 50 m'den fazla ise ilgili noktalar kaba hatalı olarak değerlendirilmiştir. Tablo 3'de dönüşüm katsayıları ve ortalama hataları, dengelemeye alınan noktaların oranı verilmiștir. Tablo 4 'te ise farkların sınır değerleri görülmektedir.

Dönüşüm ortalama hata değerleri global doğruluk değerinin altındadır. $3 \sigma$ dışında kalan noktaların oldukça az olduğu da dikkat çekmektedir. SYM 6'da diğerlerine göre daha fazla noktanın elimine olmasının nedeni SYM 5 ve 6 'da veri boșluklarının olmasıdır. Göreceli olarak SYM 6 daha fazla boşluk içermektedir. SRTM'de veri 
boşlukları -32768 değeri ile (yükseklik) temsil edilir.

Tablo 4. Yerel SYM-SRTM1 arası en büyük ve en küçük farklar (m)

\begin{tabular}{lcc}
\hline SYM No & $\Delta H_{\max }$ & $\Delta H_{\min }$ \\
\hline 1 & 253 & -272 \\
2 & 209 & -156 \\
3 & 389 & -247 \\
4 & 422 & -589 \\
5 & 126 & -110 \\
6 & 221 & -221 \\
\hline
\end{tabular}

Tablo 5. Yerel SYM-SRTM1 doğrudan karşılaştırma istatistikleri (m)

\begin{tabular}{lccc}
\hline SYM No & $m$ & $s$ & $\Delta \bar{H}$ \\
\hline 1 & \pm 7.09 & \pm 5.02 & 2.36 \\
2 & \pm 4.95 & \pm 3.82 & 2.68 \\
3 & \pm 7.17 & \pm 4.88 & 1.47 \\
4 & \pm 8.92 & \pm 6.12 & 3.36 \\
5 & \pm 9.16 & \pm 6.63 & 3.07 \\
6 & \pm 9.89 & \pm 7.37 & 3.79 \\
\hline
\end{tabular}

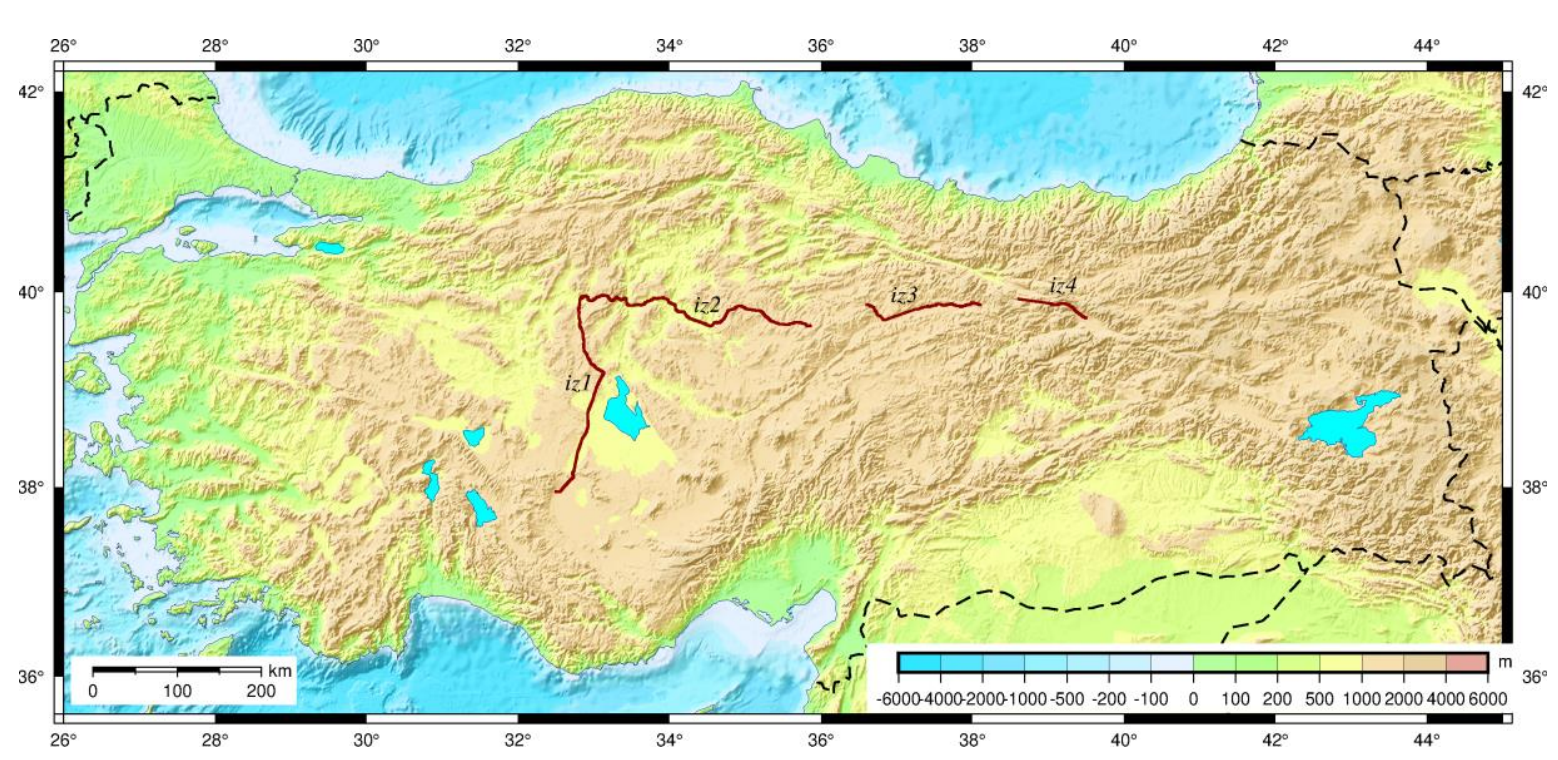

Şekil 2. Proje kapsamında kullanılan DGNSS izleri
Tablo 6. DGNSS izleri SRTM1 doğrudan karşılaştırma istatistikleri

\begin{tabular}{ccccc}
\hline$\dot{\mathrm{I} z}$ & $m(\mathrm{~m})$ & $s(\mathrm{~m})$ & $\Delta \bar{H}(\mathrm{~m})$ & Nokta Sayısı \\
\hline 1 & \pm 6.09 & \pm 4.35 & 2.09 & 5744 \\
2 & \pm 5.00 & \pm 4.06 & 3.92 & 8650 \\
3 & \pm 5.25 & \pm 4.70 & 4.49 & 2574 \\
4 & \pm 7.59 & \pm 6.04 & 5.68 & 1485 \\
\hline
\end{tabular}

Datum farklılığının az olması düșüncesinden hareketle doğrudan yükseklik karşılaştırması da yapılmıștır. (Bkz. (5) eşitlikleri). Burada da $3 \sigma=50 \mathrm{~m}$ üstü farklar hesaba katılmamıştır. Sonuçlar Tablo 5 'te görülmektedir. Bu şekilde elde edilen karesel ortalama hata değerlerinin birbirine yakın olduğu görülmektedir. $\Delta \bar{H}$ değerleri ortalama datum farklılığına işaret etmektedir.

SRTM1'in yerel SYM'den 2-3 m arası daha yüksek olduğu görülmektedir. Bu datum farkı global doğruluğun oldukça altındadır.

\subsection{DGNSS İzleri ile Doğruluk Araştırması}

Global SYM'lerde doğruluk araştırması belli güzergâhlar boyunca toplanmış izler (bir dizi nokta koordinatı) ile yapılabilir. Bildirici vd. (2008) DGNSS cihazı ile uzun izler toplayarak SRTM3 verilerini analiz etmiștir. Bu verilerden seçilen $4 \mathrm{iz}$ SRTM1 ile karşılaştırılmıştır. Veriler araç ile toplandığından ortalama anten yüksekliği $1.5 \mathrm{~m}$ kabul edilerek tüm yüksekliklerden çıkartılmıştır. 


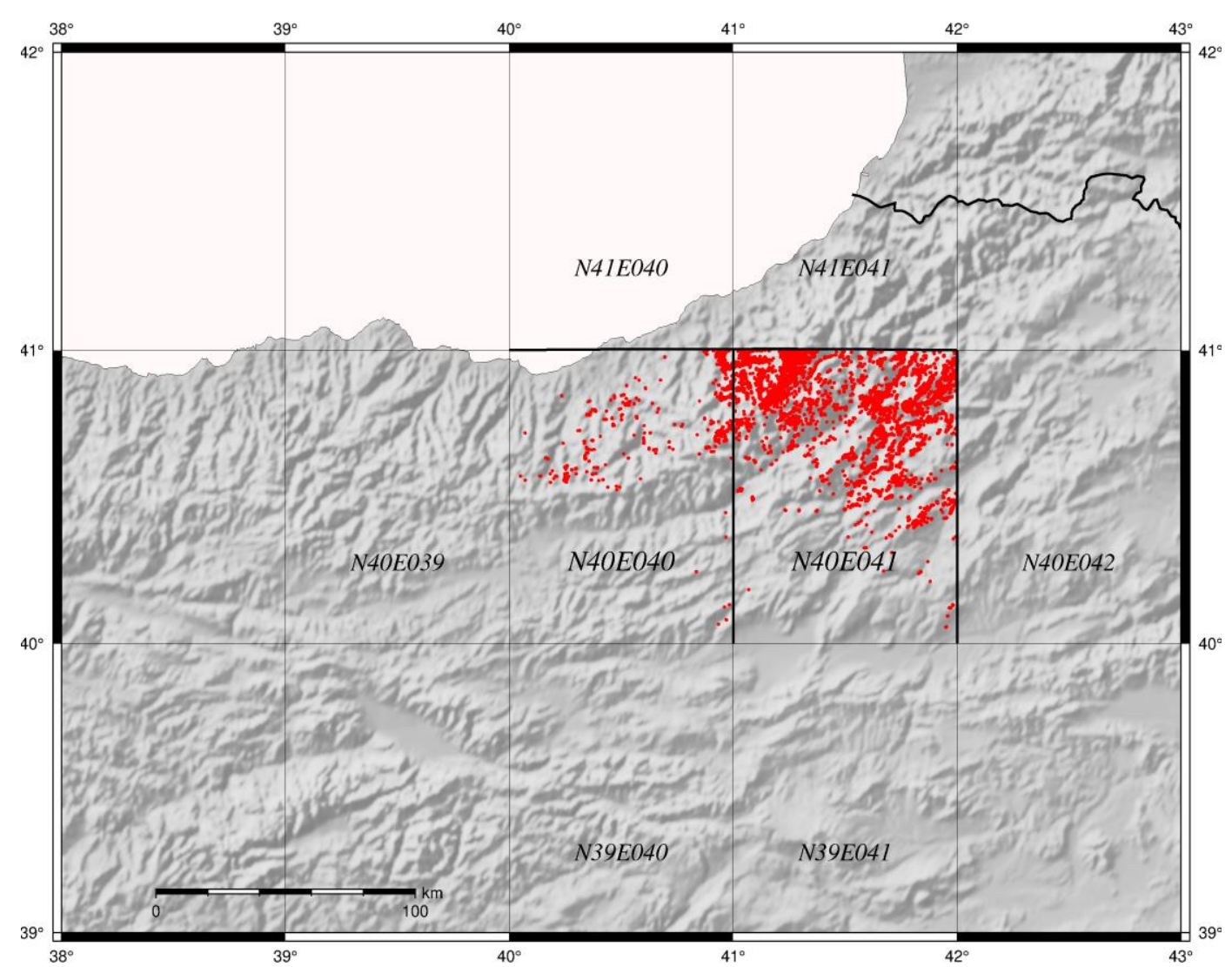

Şekil 3. Boşlukları doldurulan paftalar ve komşu paftalar (Boşluklar kırmızı noktalar ile gösterilmiştir.)

DGNSS verileri daha doğru olarak kabul edilmiş, $H_{\text {SRTM } 1}-H_{D G N S S}$ farkları istatistiksel olarak analiz edilmiştir. DGNSS cihazlarının oluşturduğu NMEA standardı (NMEA, 2019) verilerde yükseklikler EGM96 jeoit modeline göre dönüștürülmüș olduğundan düșey datum dönüșümü gerekli değildir. Bu nedenle doğrudan karşılaştırma yapılmıştır (Bkz. (5) eşitlikleri). Burada da farklar $50 \mathrm{~m}$ altında ise değerlendirmeye alınmıştır. Karşılaştırma istatistikleri Tablo 6'da yer almaktadır. Tablodaki sonuçlar yerel SYM istatistiklerine yakın olup, yerel SYM sonuçlarını teyit etmiştir.

\subsection{Veri Boşlukları}

Türkiye'yi kapsayan SRTM1 verileri incelendiğinde N40E040 ve N40E041 paftalarında veri boşlukları olduğu tespit edilmiştir. Veri boşluklarının bir kısmı $41^{\circ}$ paraleli üzerinde paftaların kuzey kenarındadır. Bu iki paftanın kuzeyindeki paftaların güney kenarlarında veri boşluğu bulunmamaktadır. Bu, aynı noktaların bir paftada yüksekliği varken diğerinde olmadığ anlamına gelmektedir.

Aynı bölgeye ait DTED2 dosyaları ile yapılan datum dönüşümü parametreleri belirlenmiş olduğundan yüksekliği olmayan noktaların yükseklikleri DTED verilerinden datum dönüşümü yapılarak tamamlanmıștır. N40E040 ve N40E041 dosyaları için datum dönüşümü parametreleri farklı olduğu için iki dosya arasında ve komşu paftalarla boşluk doldurma nedeniyle kenarlașma problemleri ortaya çıkabilir. $\mathrm{Bu}$ amaçla proje kapsamında yazılım geliştirilerek N40E040 ve N40E041 paftalarına komşu paftalarda kenarlaşma analizi yapılmıştır (Şekil 3). Bu analiz sonucu pafta kenarlarında yüksekliği farklı olan noktalarda iki paftadan alınan yüksekliklerin ortalaması iki paftaya aktarılmıștır. Bu iki pafta ve komşu paftalar arasında yalnızca 4 kenarda uyumsuzluk görülüp, düzeltmeler yapılmıștır. Tablo 7'de pafta kenarlarında yüksekliği aynı olmayan nokta sayısı ve mutlak değer olarak maksimum farklar gösterilmiștir.

Tablo 7'de kenarlaşma farklarının özellikle N41E041 N40E041 paftaları arasında oldukça yüksek olduğu dikkat çekmektedir. Daha önce de ifade edildiği gibi N41E041 güney kenarında bulunan noktalar N40E041 kuzey kenarında boş durumdadır. Bu bölge boșlukları doldurulmamıș SRTM3 verilerinde de Türkiye'de en yoğun boșluk olan bölgedir (Bildirici vd., 2008). Radar gölgesi nedeniyle oluştuğu değerlendirilebilecek boşluklar bölgedeki sıra dağlara paralel çizgiler üzerinde toplanmaktadır. SRTM1'de bu bölgede boşluklar doldurulmuş, ancak iki paftada ilginç bir şekilde boşluklar bırakılmıștır. Bu çalışmada farklar yüksek olmasına rağmen ortalama alınarak kenarlaşma sağlanmıştır. Ancak bu bölgede SRTM verilerinin güvenli olmadığı da bilinmelidir. 
Tablo 7. Veri boşlukları doldurulan paftalarda kenarlaşma analizi

\begin{tabular}{ccc}
\hline Kenar & Kenarlaşmayan nokta & Maksimum fark \\
\hline N40E040 N40E041 & 64 & $43 \mathrm{~m}$ \\
N40E041 N40E042 & 20 & $54 \mathrm{~m}$ \\
N41E040 N40E040 & 29 & $99 \mathrm{~m}$ \\
N41E041 N40E041 & 523 & $241 \mathrm{~m}$
\end{tabular}

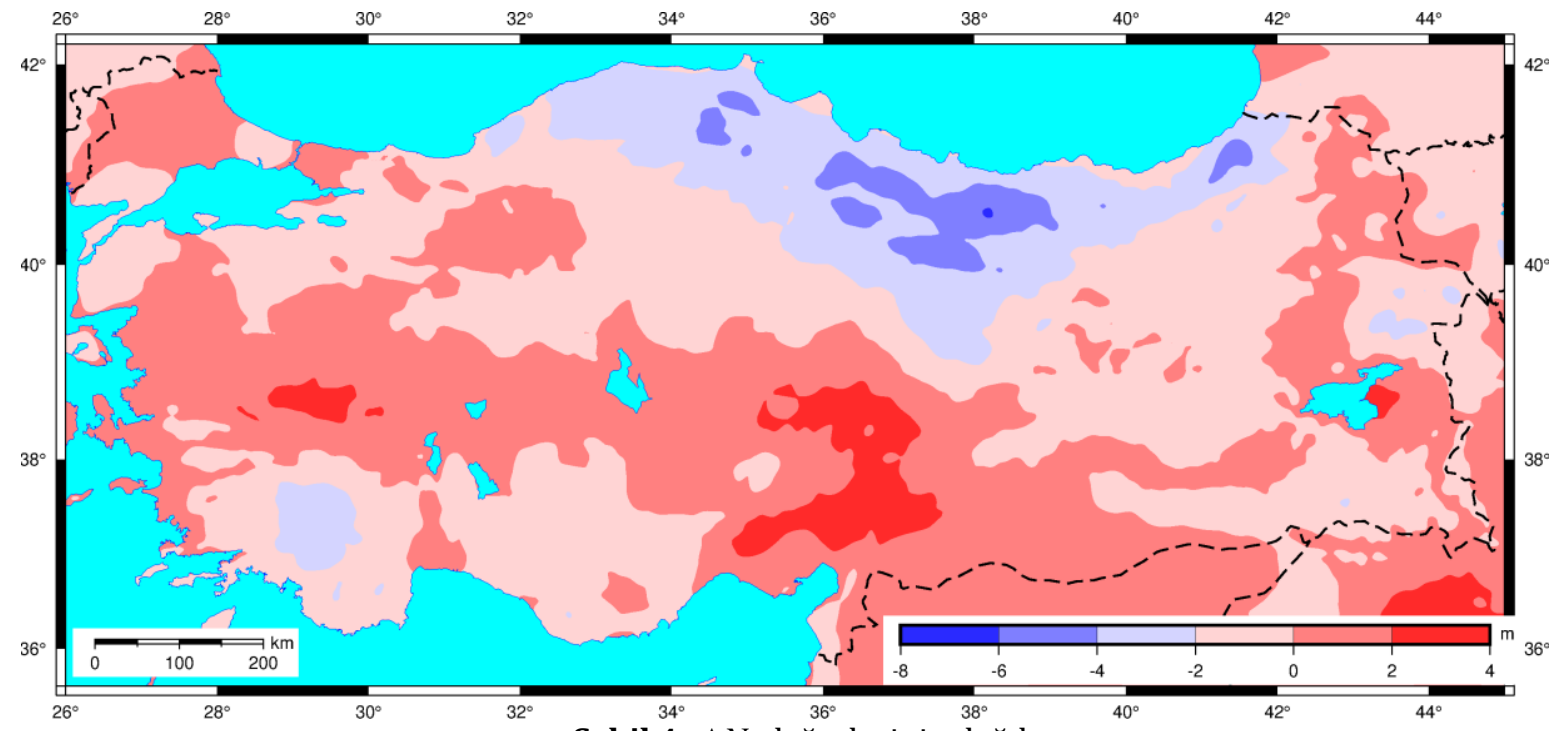

Şekil 4. $\Delta N$ değerlerinin dağılımı

\subsection{Düşey Datumun EGM08'e Dönüşümü}

Proje kapsamında olușturulan boșlukları doldurulmuş veri setinin EGM08 datumuna dönüştürülerek yayınlanmasına karar verilmiştir. Uzaktan algllama teknikleri ile üretilen SYM'lerde ölçülen yükseklik elipsoidal yüksekliktir $(h)$. Coğrafi koordinatlardan hesaplanan jeoit ondülasyonu $(N)$ elipsoidal yükseklikten çıkartılarak ortometrik yüksekliğe $(H)$ geçilir.

$$
\begin{gathered}
h=H+N \\
h=H_{E G M 96}+N_{E G M 96} \\
h=H_{E G M 08}+N_{E G M 08} \\
H_{E G M 08}=H_{E G M 96}+N_{E G M 96}-N_{E G M 08}
\end{gathered}
$$

Buna göre SRTM yüksekliklerine $\Delta N=N_{E G M 96}-N_{E G M 08}$ toplanarak düşey datum dönüşümü gerçekleștirilir. EGM96'nın çözünürlüğü 30', EGM08'in çözünürlüğü 5 ' olup, SYM çözünürlüğüne göre çok daha kabadır. Bu çalışmada jeoit değişimi 3' çözünürlükte hesaplanmıştır.

Türkiye ve çevresinde $\Delta N$ farkları -6.19 ile 3.68 arasında değișmektedir. Şekil 4'te $\Delta N$ değerlerinin Türkiye'de dağılımı görülmektedir.

$\Delta N$ değerlerinden oluşan matris/dosya çözünürlüğü SRTM1 çözünürlüğünden düşük olduğundan, iki aşamada EGM08 datumuna geçiş öngörülmüştür:
- $\Delta N$ değerleri ile gmt surface yazılımı kullanılarak SRTM1 ile aynı çözünürlükte matrisler/dosyalar üretilmesi,

- $\mathrm{Bu}$ matrislerin TSYM1 ile toplanarak EGM08 datumuna geçiş yapılması

$\mathrm{Bu}$ işlem sonucunda surface yazılımı $1^{\circ} \times 1^{\circ}$ pafta bazında yüzey oluşturduğundan EGM08'e dönüştürülmüş paftalarda kenarlaşma kontrolleri ve gerekli ise düzeltmeleri yapılması gerekmektedir.

Datum dönüşümünün etkisini görebilmek için yerel SYM ile karşılaştırılmış olan 6 paftada (Tablo 2) EGM08 dönüșümü yapılmış ve bu paftaların tekrar yerel SYM karşılaştırması gerçekleştirilmiştir. Tablo 8'de yerel SYM'den EGM08'e datum dönüşümü sonrası karesel ortalama hatalar ile $\Delta N$ değerlerinin sınır değerleri tam sayı olarak görülmektedir. Buradaki datum düzeltmeleri global SYM doğruluğunun (16 m) çok altında olup, bu düzeltmelerin yapılması yerel yüksekliklerle uyum açısından dikkat çeken bir katkı sağlamamıştır. Tablo 8 ve 3 karşılaştırıldığında bu durum açık olarak görülmektedir.

Datum dönüşümü önemli bir katkı sağlamamakla birlikte gerçekleştirilmiş; TSYM1 olarak adlandırılan veriler, kenarlașma durumları da kontrol edilerek http://galileo.ktun.edu.tr /tsym 1 adresinden yayınlanmaya başlanmıştır. 
Tablo 7. Yerel SYM-TSYM1 farklarının karesel ortalama hataları ve $\Delta N$ istatistiği (m)

\begin{tabular}{lcccc}
\hline SYM No & $m_{0}$ & $\Delta N_{\max }$ & $\Delta N_{\min }$ & $\Delta N_{\text {ort }}$ \\
\hline 1 & 6.66 & 0 & -1 & -0.06 \\
2 & 4.16 & 0 & -1 & -0.05 \\
3 & 7.02 & 2 & -1 & 0.32 \\
4 & 7.94 & 2 & -1 & 1.02 \\
5 & 8.58 & 0 & -3 & -1.44 \\
6 & 8.99 & 0 & -4 & -1.31 \\
\hline
\end{tabular}

\section{SONUÇ ve ÖNERILER}

Yeryüzü kara parçalarının büyük bölümlerini kapsayan global SYM verilerinden biri olan SRTM1 veri setinin Türkiyeyi içine alan paftaları yerel SYM ve DGNSS izleri ile karşılaştırılmıştır. SRTM1'in doğruluğu $\pm 7-9 \mathrm{~m}$ olarak bulunmuştur. Buna göre Türkiye ve yakın çevresinde SRTM, global doğruluğuna göre daha iyi bir performansa sahiptir. $\mathrm{Bu}$ makalede değinilmeyen ancak ilgili projede incelenen ASTER SYM verilerinin doğruluğu ise $\pm 7-12 \mathrm{~m}$ arasındadır. ASTER bu bölgede de Dünya genelindeki performansına sahiptir.

Doğruluk ve çözünürlük açısından 1" çözünürlüklü global sayısal yükseklik modelleri (SRTM ve ASTER) 1:50 000 ölçekli bir topografik harita ile eşdeğer yükseklik bilgisi sunmaktadır. Bu bağlamda bu verilerden 1:50 000 ölçekli topografik harita yapımında yararlanılabilir. Ölçek küçüldükçe çözünürlügün düşürülmesi gerekir. $\mathrm{Bu}$ çalışma kapsamında sunulan şekillerdeki (Şekil 1, 2 ve 3) haritalarda çözünürlük 30" seçilmiştir.

SRTM ve yerel SYM verilerinin elde ediliş yöntemi nedeniyle karşılaștırılmasının doğru bir yaklașım olup olmadığı da düșünülebilir. Yöntem gereği SRTM bitki örtüsünün üzerinden, yerel SYM ise zeminden geçen yüzeylerdir. Ancak zeminde toplanan DGNSS izleri ile benzer sonuçlar alınması, karşılaştırmanın düşey datum dönüşümü ile yapılması bitki örtüsünün etkisinin önemsiz düzeyde olduğuna işaret etmektedir.

SRTM verilerinin yerel SYM'ye göre düşey yönde 2-3 $\mathrm{m}$ artı yönde bir datum farklılığı görülmüștür. Bu farklılık yukarıda değinilen bitki örtüsü etkisinden kaynaklanabilir. Ancak global doğruluk değerlerine göre küçüktür.

İstatistiksel analiz ve yerel-EGM96 datum dönüşümünün pafta bazında belirlenmesinden sonra SRTM1 verilerinde var olan boşluklar doldurulmuștur. Daha sonra EGM08 datumuna dönüştürülmüş veri seti (Türkiye için) kullanıma sunulmuştur.

\section{TEŞEKKÜR}

Yazarlar proje desteği nedeniyle Selçuk Üniversitesi BAP koordinatörlüğüne teşekkür eder.

\section{KAYNAKÇA}

Abbak, R. A. (2014). Effect of ASTER DEM on the prediction of mean gravity anomalies: a case study over the Auvergne test region. Acta Geodaetica et Geophysica, 49(4):491-502.

Bildirici, İ.Ö., ve Abbak, R. A. (2019). 1 Yay Saniyesi Çözünürlüklü Türkiye Sayısal Yükseklik Modelinin Oluşturulması ve Kullanım Olanaklarının Araştırılması, Selçuk Üniversitesi BAP Koordinatörlüğü 17401083 Numaralı Proje Raporu.

Bildirici,_I. Ö., Üstun, A., Uluğtekin, N. N., Selvi, H. Z., Abbak, R. A., Buğdaycl, İ, ve Doğru, A. Ö. (2008). Yerel Yükseklik Bilgileriyle Desteklenmiş SRTM Verileri Kullanılarak Türkiye için 3x3 Çözünürlüklü Sayısal Yükseklik Modelinin Oluşturulması, Tübitak 106Y130 Proje Raporu.

GDAL (2018). GDAL - Geospatial Data Abstraction Library . https://www.gdal.org/. Giriş: 01.10.2018.

GMT (2018). The Generic Mapping Tools. https://www.soest.hawaii.edu/gmt. Giriș: 01.10.2018.

HGM (2018). Sayısal Arazi Modeli 2'nci Düzey DTED. https://www.harita.gov.tr. Giriș: 01.10.2018.

JPL (2018). Shuttle radar topography mission. https://www2.jpl.nasa.gov/srtm/. Giriș: 18.1.2018.

LPDAAC (2018). Routine aster global digital elevation model. https://lpdaac.usgs.gov/ dataset_discovery/aster/aster_products_table/ astgtm. Giriş: 01.10.2018.

Luana, S., Hou, X., ve Wang, Y. (2015). Assessing the Accuracy of SRTM DEM and ASTER GDEM Datasets for the Coastal Zone of Shandong Province, Eastern China. Polish Maritime Research, 22(s1):15-20.

NMEA (2019). NMEA 0183 Standard New Version 4.11. https://www.nmea.org/content/ nmea_standards/ v411.asp. Giriş: 06.02.2019.

Pipaud, I., Loibl, D., ve Lehmkuhl, F. (2015). Evaluation of TanDEM-X elevation data for geomorphological mapping and interpretation in high mountain environments | A case study from SE Tibet, China. Geomorphology, 246:232254.

USGS (2018). Earth explorer. https://earthexplorer. usgs.gov. Giriș: 18.1.2018. 
Ustun, A., Abbak, R. A., ve Zeray Öztürk, E. (2018). Height biases of SRTM DEM related to EGM96: from a global perspective to regional practice. Survey Review, 50(358):26-35.

White, K., Bullard, J., Livingstone, I., ve Moran, L. (2015). A morphometric comparison of the Namib and southwest Kalahari dunefields using ASTER GDEM data. Aeolian Research, 19:87-95. 